\title{
A PARTE ESPECIAL DO DIREITO PENAL ENTRE CODIFICAÇÃ̃o E DESCODIFICAÇÃO: SUGESTÕES PARA UM INÍCIO DE ABORDAGEM
}

\author{
THE SPECIAL PART OF CRIMINAL CODE BETWEEN CODIFICATION \\ AND DECODIFICATION: SUGGESTIONS FOR AN INITIAL APPROACH
}

\author{
André Ribeiro Giamberardino*
}

\begin{abstract}
RESUMO: O estudo da "parte especial" do Código e do Direito Penal possibilita a proposição introdutória de diversas perspectivas de abordagem, o que enfatiza sua importância na medida em que frequentemente é nela que se subvertem princípios e garantias estabelecidos pela Constituição e pela própria teoria do fato punível positivada na "parte geral". Primeiramente, indaga-se como se configura a questão histórica do movimento moderno de codificação e aquele mais recente de descodificação, perante a profusão de leis penais especiais, na história legislativa do direito penal brasileiro. Em segundo lugar, sugere-se que a redução do âmbito de intervenção do direito penal necessita de um maior controle de legitimidade da parte especial, sob parâmetros constitucionais. Tanto sobre o legislador, reduzindo-se as possibilidades de criminalização primária às hipóteses de proteção necessária de um bem jurídico ou direito fundamental constitucionalmente referenciado, como sobre o julgador, constitucionalizando-se também a interpretação, em prol da abertura a uma postura mais ousada que aproxime o estudo da parte especial ao tema do controle de constitucionalidade, em particular aquele difuso e em via incidental ou através da interpretação conforme a Constituição.
\end{abstract}

PALAVRAS-CHAVE: Direito Penal. Codificação. Parte Especial. Constitucionalização.

ABSTRACT: The study of the "special part" of the Penal Code provides an introductory proposition from many angles of approach, which emphasizes its importance whereas it's often in this field that the principles and guarantees established by the Constitution and by the theory of Criminal Law presented in the "general part" are undermined. First of all there is the question of the profusion of special penal laws, outside the Penal Code, and how the movements of modern codification and the latest decodification take place in the legislative history of Brazilian criminal law. Secondly, it is suggested that the reduction of the intervention of criminal law requires a better control of legitimacy of the special part, under constitutional parameters. On the one hand it concerns the legislature, reducing the possibility of primary criminalization to the strictly necessary cases which concern the harm to a fundamental right referred by the Constitution. On the other hand also the judicial interpretation should be constitutionalized, through the approximation between the study of the special part and the subject of the constitutionality control, specially by its diffused model.

KEYWORDS: Criminal Law. Codification. Special Part of Criminal Code. Constitutionalisation.

* Mestre em Direito (UFPR) e em Criminologia (Università degli Studi di Padova), Especialista em Direito Penal e Criminologia (ICPC/UFPR). Advogado em Curitiba - PR. 


\section{INTRODUÇÃ̃o}

O Código Penal brasileiro é dividido, como se sabe, em uma parte geral e outra especial: a primeira contendo definições, regras e princípios gerais sobre a ação, o crime e a pena conforme a respectiva teoria adotada; e a segunda composta pelos tipos penais organizados como elenco normativo ${ }^{1}$ de condutas (fattispecie) tipificadas mediante descrições de ações humanas cometidas na forma comissiva ou omissiva. ${ }^{2}$

Deixando de lado a problemática metodológica inerente à relação entre o geral e o particular ${ }^{3}$, pode-se entender, desde um ponto de vista formal, a parte especial como o conjunto dos enunciados hipotéticos que prescrevem sanções - penas em abstrato - a determinadas condutas. Em outros termos, é a partir da parte especial que se preencherá a premissa maior - se adotado o raciocínio lógico-dedutivo do silogismo ${ }^{4}$ - ou a regra a partir da qual será produzida a norma pelo intérprete no caso concreto - considerandose o giro linguístico e a perspectiva hermenêutica.

É comum se dar menor atenção ao estudo da parte especial em relação à parte geral, considerando-a de certa forma entediante. Ao mesmo tempo em que se visualiza na parte geral o alto nível de abstração e a riqueza conceitual próprias de temas essencialmente filosóficos - conforme se vê especialmente na Alemanha -, o interesse pela parte especial fica restrito, em regra, a situações em que ele se faz estritamente necessário, ou seja, na prática forense ou se consistir em conteúdo exigido por concursos públicos. Soma-se a tudo isso a circunstância histórico-política de a origem da parte geral ser diretamente referenciada ao direito penal moderno/iluminista, despertando, portanto, maior interesse àqueles que saudavelmente lutam por um direito penal mínimo.

As consequências de tal distanciamento, entretanto, são de todo negativas. No plano da produção doutrinária sobre a parte especial, a regra é a subordinação às condições de interesse retro citadas, quais sejam: produção teórica com olhar estreito

1 Não se trata, desde logo, da concepção objetiva de BINDING como sendo o tipo valorativamente neutro e composto apenas por elementos descritivos, cf. SANTOS, Juarez Cirino dos. Direito Penal: Parte Geral, p. 106.

2 SANTOS, Juarez Cirino dos. Direito Penal: Parte Geral, p. 3: "O tipo legal descrito em forma positiva cria um dever jurídico de abstenção de ação - por exemplo, subtrair para si ou para outrem, coisa alheia móvel (art. 155, CP); o tipo legal descrito em forma negativa cria um dever jurídico de ação - por exemplo, deixar de prestar assistência, quando possível fazê-lo sem risco pessoal, à criança abandonada ou extraviada, ou à pessoa inválida ou ferida... (art. 135, CP)".

3 Sobre, v. ALVAREZ GARCÍA, Francisco Javier. "Relaciones entre la parte general y la parte especial del derecho penal". Anuario de Derecho Penal y Ciencias Penales, p. 1009-1021.

4 BECCARIA, Cesare. Dos delitos e das penas, p. 17: "O juiz deve fazer um silogismo perfeito. A maior deve ser a lei geral; a menor, a ação conforme ou não à lei; a consequência, a liberdade ou a pena. Se o juiz for obrigado a elaborar um raciocínio a mais, ou se o fizer por sua conta, tudo se torna incerto e obscuro". Observa-se que Beccaria reconhecia problemas relativos à concepção de premissa menor, cf. PRIETO SANCHÍS, Luis. La filosofía penal de la Ilustración., p. 107-8. 
sobre a prática forense ou voltada à síntese do conteúdo exigido em concursos públicos. É evidente que o tema trata de um estudo essencialmente voltado à prática, porém isto não implica uma abordagem acrítica ou monodisciplinar. Ocorre que saber doutrinário e jurisprudencial se relacionam como em um círculo vicioso, legitimando-se reciprocamente; sendo restrito o número de obras e reflexões que tratem de aspectos gerais da parte especial $^{5}$, dentre os quais sua intensa correlação com o respectivo nível de constitucionalização do direito penal em dado ordenamento.

É à parte especial que cabe, afinal, a delimitação concreta do âmbito de criminalização primária - por meio de suas regras construídas como preceito e sanção e a realização dos princípios informadores do direito penal moderno como taxatividade e lesividade ${ }^{6}$, e isto não é pouco: chegou a ser caracterizada por PISAPIA, em 1948, como "o único verdadeiro e próprio direito penal". ${ }^{7}$

Mesmo se exagerada a afirmação, não se pode negar ou ignorar que da parte especial emergem temas politicamente fundamentais à luta pela construção de um direito penal efetivamente mínimo e subsidiário, inviável sem o empenho teórico crítico sobre este que é o lugar por excelência das escolhas político-criminais ${ }^{8}$ do legislador.

É apenas na parte especial que se poderá pôr à prova a compatibilidade dos critérios utilizados para a criminalização de dado comportamento com os direitos fundamentais para os quais se considera a tutela penal uma forma de proteção legítima. Assim, se "a parte especial é o espelho dos bens jurídicos que o legislador intende tutelar e das agressões às quais julga serem merecedoras de sanções penais", locus de realização de um controle de legitimidade de caráter constitucional, seja pela cotidiana interpretação conforme à Constituição, seja com o exercício de controle difuso de constitucionalidade, no caso concreto.

5 PADOVANI, Tullio; STORTONI, Luigi. Diritto penale e fattispecie criminose. Introduzione alla parte speciale del diritto penale, p. 14. Não se pode, porém, generalizar; vale v. tese de doutorado recentemente apresentada: SILVEIRA, Fabiano Augusto Martins. Do Crescimento do Direito Penal: medições, análises e interação entre ciência e política no processo de reforma legislativa. 2008. Tese (Doutorado em Direito) - Universidade Federal de Minas Gerais e também SALES, Sheila Jorge Selim de. Escritos jurídico-penais. 2. ed. Belo Horizonte: Del Rey, 2005; especialmente no que tange à primeira parte do livro. Da mesma autora, v. SALES, Sheila Jorge Selim de. "Parte especial do código e parte especial do direito penal: o problema da legislação complementar, descodificação e recodificação, critérios para recodificação - novas tendências”. Ciências Penais, v. 1, 2004, São Paulo: Associação Brasileira de Professores de Ciências Penais, p. 134-170.

6 CADOPPI, Alberto; VENEZIANI, Paolo. Elementi di Diritto Penale: Parte Speciale, p. 50; STORTONI, Luigi. "Introduzione alla parte speciale". Introduzione al sistema penale: Vol. 1, p. 411.

7 PISAPIA, Gian Domenico. Introduzione alla parte speciale del diritto penale, p. 18: "l'unico vero e proprio diritto penale".

${ }^{8}$ CADOPPI, Alberto; VEnEZIANI, Paolo. Elementi di Diritto Penale: Parte Speciale, p. 6-7.

9 STORTONI, Luigi. "Introduzione alla parte speciale". Introduzione al sistema penale: Vol. 1, p. 417: "la parte speciale è lo specchio dei beni giuridici che il legislatore intende tutelare e delle aggressioni ad essi che ritiene meritevoli di sanzione criminale". 
$\mathrm{O}$ ponto central se encontra, enfim, na hipótese de que um direito penal mínimo e subsidiário deve ser construído no caso concreto e não apenas em abstrato, o que hoje se pode (tentar) fazer através de sua constitucionalização pela interpretação. A premissa é que mesmo um "direito penal máximo" em abstrato é em grande parte meramente simbólico e persegue uma mínima percentagem dos comportamentos a que criminaliza ${ }^{10}$; sendo que eventual concretização de um reducionismo legislativo (indiscutivelmente necessária) não levaria, automaticamente, a uma redução da punição ou transformação dos critérios de seletividade.

Não se pretende aprofundar qualquer tema, mas apenas indicar sugestões do que seria um "início de abordagem crítica" da parte especial, o que passa: (a) pela compreensão dos fenômenos de codificação e descodificação nos sistemas de direito europeu-continental e a pecularidade da história legislativa penal brasileira sempre marcada por vasta legislação extravagante; (b) pela crítica atual da profusão de leis penais ligadas a um direito penal cada vez menos atento ao princípio da lesividade; (c) pela reflexão sobre a hipótese de que um direito penal mínimo no plano prescritivo não basta, sendo indispensável sua concretização por meio de uma interpretação constitucional atenta à perspectiva hermenêutica, e que realize constante e rígido controle de legitimidade a partir da verificação de qual bem jurídico (ou direito fundamental) é protegido pelo tipo penal.

\section{ENTRE CODIFICAÇÃ̃O E DESCODIFICAÇÃO}

A divisão entre uma parte geral e outra especial não é ontológica e sequer antiga, mas relativa, histórica e recente, na medida em que é produto da sistematização desencadeada pelo movimento de tecnicização da ciência jurídica e codificação em propulsão na Europa dos séculos XVIII e XIX."11

Poder-se-ia dizer assim (não fosse a ilogicidade terminológica) que a parte especial antecede historicamente a parte geral. Antes desta, diante dos "elencos de comportamentos criminalizados" questões conceituais - como a definição de tentativa, por exemplo exigiam consulta à doutrina. ${ }^{12} \mathrm{~A}$ parte geral é produto de um processo de progressiva

${ }^{10}$ Para o desenvolvimento dessa tese, v. PAVARINI, Massimo. "Per un diritto penale minimo: "in the books' o 'in the facts'? Discutendo con Luigi Ferrajoli”. Dei Delitti e Delle Pene, p. 148 e ss.

${ }^{11}$ STORTONI, Luigi. "Introduzione alla parte speciale". Introduzione al sistema penale: Vol. 1, p. 412-3. Sobre a questão na tradição anglo-saxã da common law, v. CADOPPI, Alberto. "Presentazione". Omnis definitio in jure periculosa? Il problema delle definizioni legali nel diritto penale, p. 15 e ss. Para uma leitura mais aprofundada sob perspectiva histórica v. TARELLO, Giovanni. Storia della cultura giuridica moderna: Assolutismo e codificazione del diritto. Vol. 1. Bologna: Il Mulino, 1976.

${ }^{12}$ CADOPPI, Alberto; VENEZIANI, Paolo. Elementi di Diritto Penale: Parte Speciale, p. 5. Observe-se inclusive que a postura iluminista se contrapõe a este ponto, cf. CATTANEO, Mario. Illuminismo e legislazione, p. 16: "La reazione polemica contro la posizione che avevano le opinioni dei giuristi, dei 'dottori', nell'epoca del diritto comune, produce nel pensiero illuministico una generale sfiducia verso la scienza giuridica: questo atteggiamento è collegato con l'idea della semplicità delle leggi". 
abstração de disposições antes referentes a crimes específicos. ${ }^{13} \mathrm{~A}$ reforma penal iluminista, como se sabe, funda o direito penal moderno a partir do princípio de estrita legalidade: perante a multiplicidade de fontes e um desordenado elenco de comportamentos incriminados, o que se quer é acima de tudo certeza e segurança. Não por outro motivo se consagra ao Príncipe o monopólio do exercício da violência e se passa a buscar a (de) limitação de tal intervenção por meio da lei, que haveria de dizer tudo e de forma clara, inclusive reduzindo o espaço para interpretação do juiz. Nesse sentido, enfim, o lugar do código:

É no período iluminista que é concebida - como se sabe - a própria idéia de código em sentido moderno. Beccaria e seus seguidores - e em particular Bentham, que cunhará o próprio termo 'codificação' (codification) - vêem ainda no código o único e verdadeiro instrumento legislativo capaz de submeter toda situação jurídica à vontade da lei, sendo capaz assim de impedir ao juiz que interprete a lei. A noção de código tem os braços dados, portanto, com aquela de definições legislativas: é talvez apenas em um código - logo em um corpus juris dotado de organicidade e completude - que as definições normativas possam ter sua máxima força esclarecedora do direito e vinculante para o juiz. ${ }^{14}$

Além da exigência de maior clareza das descrições dos comportamentos criminalizados, era preciso reduzir toda margem de incerteza e insegurança em relação à atividade de interpretação, admitindo-se como legítima apenas aquela realizada pelo próprio legislador. ${ }^{15} \mathrm{~A}$ adoção de uma seção à parte, dita parte geral, também tem este sentido, o que vem a se expressar "com o primeiro verdadeiro código penal moderno - que é

13 ROMANO, Bartolomeo. Guida alla parte speciale del diritto penale, p. 4. Vide, por exemplo, como a tentativa aparece no Código Penal francês revolucionário (1791) enquanto admissível apenas a alguns casos de homicídio, apresentando-se já como 'regra geral' no Código napoleônico de 1810; cf. PADOVANI, Tullio e STORTONI, Luigi. Diritto penale e fattispecie criminose. Introduzione alla parte speciale del diritto penale, p. 24. V. também CADOPPI, Alberto; VENEZIANI, Paolo. Elementi di Diritto Penale: Parte Speciale, p. 9: “da un lato, dal lento emergere di istituti di parte generale attraverso la progressiva 'astrazione generalizzatrice' di figure di parte speciale; e, dall'altro, e all'opposto, dal lento attestarsi di figure di parte speciale attraverso la progressiva ‘tipicizzazione' di porzioni di istituti di parte generale".

${ }^{14}$ CADOPPI, Alberto. "Presentazione". Omnis definitio in jure periculosa? Il problema delle definizioni legali nel diritto penale, p. 7: "È in epoca illuministica che viene concepita - come è noto - la stessa idea di codice inteso in senso moderno. Beccaria ed i suoi seguaci - ed in particolare Bentham, che conierà lo stesso termine 'codificazione' (codification) - vedono anzi nel codice l'unico vero strumento legislativo capace di sottomettere ogni caso giuridico al volere della legge, e capace così di impedire ai giudici di interpretare la legge stessa. La nozione di codice va dunque 'a braccetto' con quella delle definizioni legislative: è forse solo in un codice - comunque in un corpus juris dotato di organicità e completezza - che le definizioni normative possono avere la loro massima forza chiarificatrice del diritto e vincolante per il giudice". No mesmo sentido: PRIETO SANCHÍS, Luis. La filosofia penal de la Ilustración, p. 58-9; CATTANEO, Mario. Illuminismo e legislazione, p. 13 e ss.

${ }^{15}$ CATTANEO, Mario. Illuminismo e legislazione, p. 16: "La sola interpretazione legittima per l'illuminismo è quindi l'interpretazione autentica". 
presumivelmente o código penal austríaco (c.d. 'Giuseppina') de 1787". ${ }^{16}$ Também assim o projeto jurídico produzido após a Revolução Francesa, claramente favorável à idéia de código porque essencial ao estabelecimento da igualdade entre os cidadãos ${ }^{17}$ e incluindo a previsão de uma "parte geral" com primeiros traços no código penal de 1791, e uma expressão mais articulada no código napoleônico de 1810.

Quando se fala em descodificação, está-se a referir a um fenômeno ainda mais recente consistente na perda de centralidade do código; caracterizado, em âmbito penal, pela inflação/profusão de leis penais especiais/extravagantes próprias da gana punitivista que se seguiu à queda do Welfare State nos países centrais, e que levam alguns autores a hoje falar em uma parte especial não do Código, mas do sistema penal ${ }^{18}$ :

E então se conclui, em síntese, que o direito penal, abandonado o ideal iluminista das leis 'poucas', 'simples', 'claras' e 'estáveis', em prol da realidade das leis 'muitas', 'complexas', 'confusas' e 'instáveis', entrou na era irracional da descodificação e das legislações especiais. Ou seja, da 'nebulosa' das leis penais, utilizadas como instrumento de governo da sociedade e não de tutela de bens; das leis compromissórias, de formulações indeterminadas e valorativas; das leis que privilegiam grupos sociais poderosos; das leis vazias, simbólicas, mágicas, voltadas apenas a declamar preocupações na luta contra certas formas de criminalidade; das leis 'hermafroditas', tendo a forma de lei mas conteúdo de atos administrativos; (...); das leis-expediente, do caso por caso, para sobreviverem dia após dia e quase sempre mal; das leis 'burocráticas', meramente sancionatórias de preceitos genéricos extrapenais; e leis tecnicamente desleixadas, inspiradas na 'logorréia legislativa', no 'desperdício de fattispecie', na 'liberdade da palavra' (para não dizer 'na palavra em liberdade'), e de compreensão cada vez mais árdua. ${ }^{19}$

${ }^{16}$ CADOPPI, Alberto; VENEZIANI, Paolo. Elementi di Diritto Penale: Parte Speciale, p. 3: “con il primo vero codice penale moderno - che è presumibilmente da riternersi il codice penale austriaco (c.d. 'Giuseppina') del 1787". Sobre o tema, v. TARELLO, Giovanni. Storia della cultura giuridica moderna: Assolutismo e codificazione del diritto, p. 191-222.

${ }^{17}$ CATTANEO, Mario. Illuminismo e legislazione, p. 115 e ss. Na p. 116 o autor traz exemplos retirados de cahiers produzidos durante os primeiros momentos após a Revolução: "Ecco alcuni esempi di rivendicazioni in tal senso: 'il faudrait qu'on en [delle leggi] simplifiât la forme et qu'elles formassent un code clair e intelligible à l'esprit de celui qui se trouve dans le cas de réclamer leur autorité'; 'pour mettre tout le monde à portée de se rendre justice et d'éviter bien des procès, il serait à désirer qu'on fît un code de lois, simple et lucide, sur les cas les plus ordinaires et qu'il en fût déposé un exemplaire dans chaque paroisse, pour mettre un chacun à la portée de le consulter...".

${ }^{18}$ PADOVANI, Tullio; STORTONI, Luigi. Diritto penale e fattispecie criminose. Introduzione alla parte speciale del diritto penale, p. 35 .

${ }^{19}$ MANTOVAnI, Fernando. Diritto Penale: Parte Speciale, v. I. 3. ed. Milano: Cedam, 2008, p. XVI-XVII: "E allora occorre, rassegnatamente, concludere che il diritto penale, abbandonato l'ideale illuministico delle leggi 'poche', 'semplici', 'chiare' e 'stabili', per la realtà delle leggi 'troppe', 'complesse', 'confuse' e 'instabili', è entrato nell'era irrazionale della decodificazione e delle legislazioni speciali. Cioè della 'nebulosa' delle leggi penali, usate come strumento di governo della società e non di tutela di beni; delle leggi compromissorie, dalla formulazione indeterminata, e valutative; delle leggi privilegianti potenti gruppi sociali; delle leggi vuote, simboliche, magiche, volte soltanto a declamare la sollecitudine nella lotta contro certe forme di criminalità; delle leggi 'ermafrodite', aventi la 
A descodificação é um dos componentes, nesse sentido, do processo de destruição do Estado de Direito em prol de um Estado de Polícia ${ }^{20}$, no qual falar em limites à intervenção punitiva parece ser cada vez mais um discurso acadêmico distante das posições autoritárias da classe política, dos meios de comunicação e também de grande parte da população.

Perante tudo isso, põe-se a questão se um "retorno ao código"- um movimento de recodificação - seria uma bandeira possível ou adequada a quem defende um Estado Democrático de Direito e um direito penal mínimo. Parece lógico, em uma primeira e superficial leitura, que se o direito penal é mínimo e voltado apenas à proteção dos bens ou direitos mais fundamentais do ser humano, ter-se-á um número restritíssimo de comportamentos criminalizados e tal discussão se tornaria desnecessária.

É preciso, entretanto, refletir se tal debate assim colocado faz sentido no Brasil, questionando-se: verifica-se na história da legislação penal brasileira uma verdadeira experiência de codificação seguida de uma descodificação, de forma a se poder cogitar falar em um "retorno" ao código como bandeira defensável?

A primeira experiência de codificação penal autenticamente brasileira, em seguida à declaração da independência e a Constituição de 1824, foi o Código Criminal do Império, em 1830. De inspiração iluminista, já continha uma parte geral antecedendo a especial que substituía o vasto elenco de incriminações até então vigentes pelas Ordenações Filipinas.

Porém, e sobretudo porque sendo ainda uma economia de base escravista, a marca do direito penal brasileiro continuou sendo a punição doméstica. Em outras palavras, não se "recebeu" o código penal com o "otimismo" de sua representação como uma saída rumo à segurança jurídica: em sentido bastante diverso, na verdade, fontes múltiplas seguiram em vigor - tanto extraestatais, por meio das relações escravistas, como estatais, visto que os poderes legislativos municipais tinham competência para

\footnotetext{
forma di legge, ma la sostanza di atti amministrativi; (...); delle leggi-espediente, del caso per caso, per sopravvivere giorno per giorno e pressoché sempre male; delle leggi 'burocratiche', meramente sanzionatorie di generici precetti extrapenali; nonché delle leggi tecnicamente sciatte, inspirantisi alla 'logorrea legislativa', allo ‘spreco delle fattispecie', alla 'libertà della parola' (per non dire 'alla parola in libertà'), e di sempre più ardua comprensione."

${ }^{20}$ Sobre o tema, v. entre outros: ARGUELLO, Katie. Do Estado Social ao Estado Penal: invertendo o discurso da ordem. Conferência proferida no " $1^{\circ}$ Congresso Paranaense de Criminologia" em Londrina, 2005. Disponível em: http://www.cirino.com.br/artigos/Artigo\%20Katie.pd\#; BOURDIEU, Pierre (org.). Actes de la recherche en sciences sociales: de l'État Social à l'État Pénal, n. 124, 1998, Paris: SEUIL (traduzido em: Revista Discursos Sediciosos, ano 7, n. 11, 2002, Rio de Janeiro: ICC/Revan); DE GIORGI, Alessandro. A miséria governada através do sistema penal. Tradução de Sérgio Lamarão. Rio de Janeiro: Revan / ICC, 2006; GARLAND, David. The Culture of Control: Crime and Social Order in Contemporany Society. Chicago: University of Chicago Press, 2001; WACQUANT, Loïc. As prisões da miséria. Tradução de André Telles. Rio de Janeiro: Jorge Zahar, 2001.
} 
legislar em matéria criminal ${ }^{21}$ - e não à toa já se tinha uma vasta legislação penal extravagante. $^{22}$ O Código Penal seguinte, de 1890, foi ainda mais frágil do ponto de vista político e absolutamente deslocado do lugar central que deveria, inerentemente, ocupar. Criticado por não satisfazer as demandas por segurança da época traduzidas na conservação da ordem social, "a criminalização daqueles alvos sociais - imigrantes indesejáveis, anarquistas, prostitutas e cáftens etc - foi empreendida através de leis extravagantes, ou de leis que alteravam o texto original do código". ${ }^{23}$

A inflação penal foi tanta e tão desimportante e desvalorizado feito o Código, que mediante o Decreto n. ${ }^{\circ} 22.213$, de 14 de dezembro de 1932, já com Getúlio Vargas, reconheceu-se uma obra de compilação - de autoria de Vicente Piragibe - como uma Compilação de Leis Penais:

\section{$(\ldots)$}

Considerando que o Codigo Penal Brasileiro, promulgado pelo decreto n. 847, de 11 de outubro de 1890, tem sofrido inumeras modificações, quer na classificação dos delitos e intensidade das penas, quer com a adoção de institutos reclamados pela moderna orientação da penalogia;

Considerando que essas modificações constam de grande número de leis esparsas, algumas das quais já foram, por sua vez, profundamente alteradas, o que dificulta não só o conhecimento como a aplicação da lei penal; (...)

Art. $1^{\circ}$ Fica aprovado e adotado, como Consolidação das Leis Penais, o trabalho do Sr. desembargador Vicente Piragibe, publicado sob o título "Codigo Penal Brasileiro, completado com as leis modificadoras em vigor", que a este acompanha, subscrito pelo ministro da Justiça. (... $)^{24}$

Oito anos depois, o Decreto n. ${ }^{\circ} 2.848$, de 7 de dezembro de 1940, institui o Código Penal que, com a reforma de 1984 e várias modificações, permanece em vigor até hoje. Durante o período que inicia após a Guerra também há grande montante de leis penais especiais, não obstante de diverso caráter político. ${ }^{25}$ Atualmente, enfim, o lugar ocupado pela legislação penal extravagante é imenso e constitui, em muitos casos, "microssistemas" à parte.

${ }^{21}$ BAtiSta, N.; ZAFfaroni, E.; ALAGIA, A.; SLOKAR, A. Direito Penal Brasileiro, p. 425. Sobre este ponto, observa-se que é apenas com a República e a Constituição de 1891 (art. 34, §23) que legislar em matéria penal se torna competência exclusiva da União.

${ }^{22}$ Para um elenco da legislação penal extravagante do período imperial, v. BATISTA, N.; ZAFFARONI, E.; ALAGIA, A.; SLOKAR, A. Direito Penal Brasileiro, p. 438 e ss.

${ }^{23}$ BAtiSTA, N.; ZAFfaroni, E.; ALAGIA, A.; SLOKAR, A. Direito Penal Brasileiro, p. 446. Para um elenco da ainda mais vasta legislação penal extravagante na Primeira República, v. Idem, p. 451-456.

${ }^{24}$ Art. $1^{\circ}$, Decreto 22.213, de 14 de dezembro de 1932.

${ }^{25}$ Cf. BATISTA, N.; ZAFFARONI, E.; ALAGIA, A.; SLOKAR, A. Direito Penal Brasileiro, p. 475-7. 
A atual inflação penal brasileira tem as características de seu tempo ${ }^{26}$, marcada pela adesão do legislador a uma revisitada crença no efeito intimidatório (deterrence) da criação de tipos penais e de aumento de penas, conjugada a um rigor exacerbado que paulatinamente se afasta do discurso da ressocialização em prol daquele da incapacitation ou "neutralização de inimigos". A iniciativa legislativa é em regra casuística, impulsionada pelos meios de comunicação e por interesses eleitorais. A tendência, enfim, é o fortalecimento de um direito penal que antecipa seu âmbito de intervenção pela tutela do perigo, ao invés da lesão, em contexto que cada vez mais banaliza o conceito de bem jurídico; sem falar, ainda, da elaboração de leis especiais de caráter civil ou administrativo que contêm sanções penais com o objetivo de lhes conferir "mais eficácia".

Trata-se, por fim, de partir da constatação de que o direito penal brasileiro é marcado por um fenômeno de codificação débil; observando-se que também no direito civil o processo se deu apenas em 1916 e de forma bastante peculiar. ${ }^{27}$ Tal "original não-centralidade" política e cultural do código penal, em prol de leis penais especiais, é criticável em muitos aspectos, dentre os quais: (a) incoerência metodológica e axiológica entre os critérios de criminalização (ou seja, a escolha de bens jurídicos protegidos) e os valores constitucionais; (b) põe-se de lado diversos princípios imprescindíveis ao Estado de Direito como aquele referente à taxatividade ${ }^{28}$; (c) implica a fragmentação e a redução da efetividade do sistema de justiça criminal, caso se opere em uma perspectiva que valorize tal argumento; (d) formam-se “constelações autônomas" de tipos penais com tendência centrífuga em relação à parte geral, enfraquecendo-a:

Sublinhe-se acima de tudo como a colocação fora do código de corpos normativos penais comporta o perigo de uma atenuação da própria eficácia das normas da parte geral e, consequentemente, da força garantista que revestem..$^{29}$

26 Sobre o tema v. SILVEIRA, Fabiano Augusto Martins. Do Crescimento do Direito Penal: medições, análises e interação entre ciência e política no processo de reforma legislativa. 2008. Tese (Doutorado em Direito) Universidade Federal de Minas Gerais.

27 Vide entre muitos outros: TEPEDINO, Gustavo. "Crise das fontes normativas e técnica legislativa na parte geral do Código Civil de 2002". A Parte Geral do Novo Código Civil: estudos na perspectiva civil constitucional. 3.ed. Rio de Janeiro: Renovar, 2007; FONSECA, Ricardo Marcelo. "Dal diritto coloniale alla codificazione: appunti sulla cultura giuridica brasiliana tra settecento e novecento". Quaderni fiorentini per la storia del pensiero giuridico moderno, 33/34, Milano: Giuffrè, p. 963-984; FACHIN, Luiz Edson (Org.). Repensando fundamentos do direito civil contemporâneo. Rio de Janeiro: Renovar, 1998.

28 Vê-se como a costumeira técnica legislativa não se importa com a clareza do texto quando se utiliza grande quantidade de verbos, todos "núcleos do tipo"; um exemplo, dentre tantos, é o art. 33, caput, da Lei n. 11.343 (Lei de Drogas), de 23 de agosto de 2006, tipificando o ato de: "Importar, exportar, remeter, preparar, produzir, fabricar, adquirir, vender, expor à venda, oferecer, ter em depósito, transportar, trazer consigo, guardar, prescrever, ministrar, entregar a consumo ou fornecer drogas, ainda que gratuitamente, sem autorização ou em desacordo com determinação legal ou regulamentar (...)".

29 STORTONI, Luigi. "Introduzione alla parte speciale". Introduzione al sistema penale: Vol. 1, p. 429: "Va innanzitutto rilevato come la collocazione fuori dal codice di corpi normativi penali comporti il pericolo di una 
Na medida em que leis especiais sempre apresentam características correspondentes a seus períodos de vigência, o que se pode notar atualmente é sua apresentação na forma de "legislação penal de emergência", contrapondo-se assim a uma cultura de respeito aos valores constitucionais.

\section{CONSTITUCiONALIZAÇÃ̃O DO DIREITO PENAL}

O direito penal brasileiro "especial” parece nunca ter passado por uma sistematização por meio da codificação mas, em sentido oposto, tendeu e tende à expansão. A profusão constante de leis penais especiais é também um dos traços que marcam a desilusão do sonho iluminista de redução das incertezas na interpretação. Sabe-se, porém, que há uma diferença enorme entre criminalidade real e aparente, ou seja, entre todas as ações humanas cometidas em conformidade a um tipo penal e aquelas que são efetivamente objeto de persecução. Não se trata, evidentemente, do "discurso contra a impunidade" que reproduz a demanda pelo aumento da intervenção penal, mas tão-somente de verificar que a imensa maioria dos tipos penais existentes tem eficácia meramente simbólica ou melhor dizendo, uma 'ontológica inefetividade sancionatória": "é esta esfera do sistema de criminalização primária que determina o processo de inflação da demanda por punição simbólica, que resulta irrealizável pelo sistema de criminalização secundária" ${ }^{30}$

A seleção que é inerente a este processo implica um direito penal que "nos fatos" se caracteriza pela incidência prioritária sobre sua tradicional "clientela" de jovens desempregados e pobres - afora outros estigmas - condenados por crimes que - eis o ponto - dificilmente seriam objeto de descriminalização em um eventual "direito penal mínimo" no plano normativo.

Ressalte-se: uma ampla reforma da legislação penal pautada por critérios de descriminalização e despenalização, no sentido proposto por $\mathrm{SANTOS}^{31}$, é certamente necessária; o que se propõe à reflexão é se a intervenção penal e o encarceramento em

attenuazione della stessa efficacia delle norme della parte generale e, conseguentemente, della valenza garantista che esse rivestono". Sobre o debate v. também CADOPPI, Alberto; VENEZIANI, Paolo. Elementi di Diritto Penale: Parte Speciale, p. 41; FIORE, Carlo. "Decodificazione e sistematica dei beni giuridici". Beni e techniche della tutela penale: materiali per la riforma del codice, p. 78.

${ }^{30}$ PAVARINI, Massimo. "Per un diritto penale minimo: 'in the books' o 'in the facts'? Discutendo con Luigi Ferrajoli”. Dei Delitti e Delle Pene, p. 148: “è questa sfera del sistema di criminalizzazione primaria che determina il processo inflativo di domanda di penalità simbolica, che risulta insoddisfabile dal sistema della criminalizzazione secondaria". Sobre o tema v. SGUBBI, Filippo. Il reato come rischio sociale. Bologna: Il Mulino, 1990; e também ARGUELLO, Katie. Do Estado Social ao Estado Penal: invertendo o discurso da ordem, p. 10.

${ }^{31}$ SANTOS, Juarez Cirino dos. "A criminologia crítica e a reforma da legislação penal”. Apresentação na XIX Conferência Nacional dos Advogados/OAB. Florianópolis, 2005, p. 7 e ss. 
massa dos mais socialmente fragilizados, com base em poucas definições legais, seria diretamente vinculável à profusão de tipos penais. Nesse sentido:

Em regra o tema da despenalização é rejeitado na reflexão político-legislativa, enquanto identificação do princípio capaz de distinguir o que merece a proteção penal do que, ao contrário, pode não ser penalmente tutelado (...). Mesmo tão radicalmente distantes, tanto a política inflativa como a deflativa do direito penal restam por reproduzir, no contexto da cultura jurídico-penal na Itália, a ilusão do primado da lei penal, ambas confiando que mais ou menos justiça penal dependa simplesmente da escolha legislativa por penalizar ou despenalizar. ${ }^{32}$

A reflexão é sobre a realidade italiana mas pouco diverge da brasileira, neste ponto; sendo necessário, de qualquer forma, lutar pelas condições sociais, históricas e culturais que determinem um direito penal efetivamente mínimo (e ultima ratio) nos fatos.

Para tanto, é essencial o exercício constante, por parte dos juízes - mas também de todos os operadores do sistema - de um controle de legitimidade da lei penal, especialmente da parte especial do Código e das leis penais especiais, com base em parâmetros constitucionais.

A definição, pela descrição, de uma conduta a ser criminalizada, é tarefa evidentemente sujeita à fluidez da linguagem; e na medida em que jamais as palavras darão conta de todas as situações concretas, dá-se margem a interpretações diversas. No âmbito da parte especial o que tem ocorrido - por alguns entendido como uma disputa entre legislador e intérprete ${ }^{33}$ - é a produção de um saber eminentemente jurisprudencial legitimando uma produção legislativa descomprometida com a técnica e o rigor conceitual, ambos axiologicamente orientados segundo uma "cultura emergencial" e, assim, não raro contradizendo princípios e preceitos constitucionais ou mesmo normas da própria parte geral do Código Penal.

Um ponto prévio a se considerar - de alta complexidade e que foge ao objeto deste texto - é a superação de um paradigma filosófico centrado na consciência e em uma relação na qual o sujeito domina o seu objeto, estando a linguagem entre eles $^{34}$, em prol de outra concepção, segundo a qual "a linguagem passa da condição de objeto da

32 PAVARINI, Massimo. "Per un diritto penale minimo: 'in the books' o 'in the facts'? Discutendo con Luigi Ferrajoli”. Dei Delitti e Delle Pene, p. 151: "Di norma il tema della depenalizzazione è declinato nella riflessione politico-legislativa come individuazione del principio capace di distinguere ciò che merita di essere penalmente protetto, da ciò che invece può non essere penalmente tutelato. (...). Pur così radicalmente distanti, tanto la politica inflativa che deflativa del diritto penale finiscono per riprodurre nel contesto della cultura giuridico-penale in Italia l'illusione del primato della legge penale, ambedue confidando che più o meno giustizia penale semplicemente dipenda dalla scelta legislativa di penalizzare o di depenalizzare".

${ }^{33}$ STORTONI, Luigi. "Introduzione alla parte speciale". Introduzione al sistema penale: Vol. 1, p. 416.

${ }^{34}$ STRECK, Lênio Luiz. Hermenêutica jurídica e(m) crise, p. 157. 
reflexão para a condição de fundamento de todo pensar. Filosofar significa filosofar a partir da linguagem". 35

Conhecer tal "virada" - dita linguistic turn - é essencial por não se poder cogitar o início de uma interpretação supondo possível extrair das palavras seu "único e certo significado". É preciso reconhecer como pressuposto que o direito é feito de palavras ${ }^{36}$ que podem ser sempre manejadas pelo intérprete. ${ }^{37} \mathrm{E}$ sendo assim, as palavras da lei nada seguram. ${ }^{38}$

As definições trazidas nos tipos legais não levam em conta a fluidez da linguagem na medida em que são carregadas de estereótipos, entendidos estes como aquelas expressões cujo significado de base é encoberto por definições persuasivas e forte carga ideológica:

Os estereótipos são palavras que apresentam uma carga conotativa provocadora de associações tão fortes que a simples evocação de seus significantes motiva comportamentos ou determina opiniões. Por isso, também podemos definir um estereótipo como um termo que tem eficácia comunicativa a partir da força conotativa vinculada a seu significante. ${ }^{39}$

Projetada a noção à teoria do delito, afirma WARAT que "os elementos normativos do tipo penal constituem a autorização teórico-legal para a produção por parte do juiz de definições persuasivas", introduzindo-se, "sob a suposta aparência de uma descrição objetiva, uma dimensão ideológica não formulada na linguagem jurídica" ${ }^{40}$ No sentido

${ }^{35}$ LUDWIG, Celso Luiz. Para uma Filosofia Jurídica da Libertação, p. 93.

${ }^{36}$ Nesse sentido, v. COUTINHO, Jacinto Nelson de Miranda. "Prefácio". LOPES JR., Aury. Direito Processual Penal e a sua Conformidade Constitucional, p. xviii: "O problema é que o Direito (como, afinal, todos os campos, teorias ou ciências) é o reino, por excelência, das palavras, das imagens. Enfim, vale o argumento do mais hábil discursivamente (embora não se tenha mais a Ágora grega), pela qualidade ou - o que é pior por prevalecer pela quantidade".

${ }^{37}$ Ver sobre o tema as obras de Ludwig WITTGENSTEIN e Ferdinand SAUSSURE. Este, tido como fundador da linguística moderna, clarificou a cisão existente entre signo e significado, indicando o rompimento da relação entre significado e significante e a caracterização do signo pelos princípios da arbitrariedade, no sentido de que o significante é imotivado em relação ao significado, não havendo nenhum laço natural entre eles constatável; e pela linearidade do significante, o que quer dizer que, pelo fato de ser acústico, "seus elementos se apresentam um após o outro, formam uma cadeia"; Cf. SAUSSURE, Ferdinand. Curso de linguística geral, p. 80-84. Segundo WITTGENSTEIN, o significado de uma palavra ou frase é aferível pelo seu uso e aplicação na linguagem: “A palavra não tem significado algum quando nada lhe corresponde - É importante constatar que a palavra 'significado' é usada de um modo que vai contra a linguagem quando com ela se designa a coisa que 'corresponde' à palavra. (...). O significado de uma palavra é o seu uso na linguagem"; cf. WITTGENSTEIN, Ludwig. Investigações filosóficas, p. 37-38 ( $\S 40$ e 43). E ainda, no $§ 432$ : “Todo signo, sozinho, parece morto. O que lhe confere vida? Ele está vivo no uso. Ele tem si o hálito da vida? Ou é o uso o seu hálito?” (Idem, p. 173).

${ }^{38}$ COUTINHO, Jacinto Nelson de Miranda. "Dogmática crítica e limites linguísticos da lei”. Diálogos constitucionais, p. 229.

${ }^{39}$ WARAT, Luis Alberto. O Direito e sua Linguagem, p. 72.

40 WARAT, Luis Alberto. O Direito e sua Linguagem, p. 71. 
dado à interpretação pela hermenêutica 41 , portanto, o "conjunto das disposições (textos, enunciados) é apenas ordenamento em potência, um conjunto de possibilidades de interpretação, um conjunto de normas potenciais. O significado (isto é, a norma) é o resultado da tarefa interpretativa. Vale dizer: o significado da norma é produzido pelo intérprete". ${ }^{42}$

Assim, quem $f a z$ o tipo de injusto, "no fundo, é o intérprete ou com base na norma ou com base na compreensão do seu sentido". ${ }^{43}$ Põe-se o drama entre um apego à literalidade do texto como postura garantista e a ingenuidade desta; pois ao mesmo tempo em que se não pode cogitar permitir a extensão in malam partem da interpretação da lei penal - e mormente da lei penal especial - para além do que a lei expressamente diz, por outro não se pode mais crer que a norma está pré-contida no texto e que basta ao intérprete desvendá-la a partir de um raciocínio lógico-dedutivo.

São muitos os casos em que a vagueza e a ambiguidade ${ }^{44}$ de muitas palavras e expressões utilizadas pelo legislador permitem questionar até que ponto a necessidade de se elucidar o significado da norma no caso concreto não torna cada vez mais problemático o efetivo cumprimento da função de garantia individual inerente aos princípios da legalidade e taxatividade.

Nesse contexto é que deve incidir a força normativa da Constituição, constitucionalizando-se a própria interpretação da lei penal. Trata-se de olhar para as definições legais com "olhos desencantados" mas sem "resignação fatalista" 45 , partindo da premissa de que, sendo a lei penal a mais grave ameaça de intervenção estatal na liberdade individual, deve ser interpretada sempre de forma restritiva.

$\mathrm{O}$ direito penal constitucional decorre da consideração de uma eficácia vinculante e cogente da Constituição, e não apenas programática, a partir de um raciocínio bastante simples: se a imposição de uma pena significa a supressão ou redução institucional de

41 COUTINHO, Jacinto Nelson de Miranda. "Prefácio: O Drama, Hoje, do Direito Penal". BRANDÃO, Cláudio. Curso de Direito Penal: Parte Geral, p. XIX: "Eis o lugar do interpres, no latim, ou seja, aquele que se coloca entre duas partes, mas também o que explica: inter+pres; daí interpretāt $\square \bar{o}$, interpretāt $\square \bar{n} n i s$, interpretação, em português, com sua teoria, hermenêutica, decorrente de Hermes, o deus grego da fertilidade, filho de Zeus e Maia (filha de Atlas), que levava as mensagens dos deuses na Odisséia".

42 GRAU, Eros Roberto. Ensaio e discurso sobre a interpretação/aplicação do direito, p. 81.

43 TAVARES, Juarez. Teoria do Injusto Penal, p. 103.

44 WARAT, Luis Alberto. O Direito e sua Linguagem, p. 76-78: "Um termo é vago, em sentido lato, nos casos onde não existe uma regra definida quanto a sua aplicação. [...]. Nesta zona de incerteza é onde se apresenta o problema da vagueza. [...]. A ambiguidade, por outro lado, é um caso particular de incerteza designativa. Podemos caracterizar a ambiguidade nos casos em que um termo possui mais de um conjunto de propriedades designativas, isto é, um mesmo rótulo ou significante veicula propriedades designativas aplicáveis a âmbitos denotativos claramente diferenciáveis".

45 CADOPPI, Alberto. "Presentazione". Omnis definitio in jure periculosa? Il problema delle definizioni legali nel diritto penale, p. 29. 
um direito de alta relevância constitucional como é a liberdade individual, entender-se-á que só se poderá cogitar permitir ao Estado fazê-lo quando servir à proteção de outro bem ou direito de equiparável relevância. ${ }^{46}$

$\mathrm{O}$ conceito de bem jurídico ${ }^{47}$ funciona assim como critério/limite de criminalização do Direito Penal no Estado Democrático de Direito tendo como fonte exclusiva a Constituição. ${ }^{48}$ Sua identificação, por sua vez, deve ser realizada com rigor e antes mesmo da interpretação propriamente dita do tipo penal ${ }^{49}$, pois se este não protege um direito ou bem jurídico com relevância constitucional deve ser reconhecida sua inconstitucionalidade. Em outras palavras, a acepção de bem jurídico deve ser crítica no sentido sugerido por HASSEMER, ou seja, fazendo do próprio conceito um objeto de investigação e crítica a fim de se estar constantemente a verificar a legitimidade de cada norma penal incriminatória:

Os bens jurídicos precedem a decisão do legislador penal e consequentemente esta decisão pode ser a eles referida e criticada. (...). Estas concepções de bem jurídico se voltam sobretudo ao legislador penal e o impõem um limite à criminalização. ${ }^{50}$

Seguindo BARATTA se chega à equiparação entre bem jurídico e a noção de direitos fundamentais ou direitos humanos, em sentido amplo, como limitação para a criminalização:

O conceito de direitos humanos assume, neste caso, uma dúplice função. Primeiramente, uma função negativa concernente aos limites da intervenção penal. Em segundo lugar, uma função positiva relacionada à definição do objeto, possível mas não necessária, da tutela por meio do direito penal. ${ }^{51}$

${ }^{46}$ Sobre, v. por todos: BRICOLA, Franco. "Teoria generale del reato". Novissimo Digesto Italiano, vol. XIV. Torino: Utet, 1973, p. 7-93.

${ }^{47}$ Outras definições: são "valores relevantes para a vida humana individual ou coletiva (...) selecionados por critérios político-criminais fundados na Constituição", cf. SANTOS, Juarez Cirino dos. Direito Penal, p. 5; "são valores ético sociais que o direito seleciona, com o objetivo de assegurar a paz social, e coloca sob sua proteção para que não sejam expostos a perigo de ataque ou a lesões efetivas", cf. TOLEDO, Francisco de Assis. Princípios básicos de direito penal, p. 16; é "a relação de disponibilidade de um indivíduo com um objeto, protegido pelo Estado, que revela seu interesse mediante a tipificação penal de condutas que o afetam”, cf. ZAFFARONI, Eugenio Raúl; PIERANGELI, José Henrique. Manual de direito penal brasileiro, p. 439.

${ }^{48}$ SANTOS, Juarez Cirino dos. Direito Penal, p. 15-6.

${ }^{49}$ STORTONI, Luigi. "Introduzione alla parte speciale”. Introduzione al sistema penale: Vol. 1, p. 439.

${ }^{50}$ HASSEMER, Winfried. "Il bene giuridico nel rapporto di tensione tra costituzione e diritto naturale". Dei Delitti e Delle Pene, p. 105: "I beni giuridici precedono la decisione del legislatore penale e di conseguenza questa decisione può essere riportata ad essi e criticata. (...). Queste concezioni del bene giuridico si rivolgono soprattutto al legislatore penale e gli impongono un limite alla criminalizzazione."

${ }^{51}$ BARATTA, Alessandro. "Principi di diritto penale minimo. Per una teoria dei diritti dell'uomo come oggetto e limite della legge penale". Dei Delitti e Delle Pene, p. 443: "Il concetto di diritti umani assolve, in questo 
Assim, o ônus de justificação do legislador é remetido para uma dimensão empírica $^{52}$ e se torna necessário que o tipo penal proteja um direto de relevância constitucional e nesse sentido verificável, sob risco de se tratar de uma criminalização ilegítima. Além disso, a intervenção penal deve ser efetivamente necessária, e não a "primeira resposta" mesmo porque dificilmente será a mais socialmente adequada.

O exame da constitucionalidade de cada tipo penal é tarefa anterior, portanto, à classificação do tipo segundo os diversos critérios existentes, e que exige a revisão de todos os tipos penais produzidos nas últimas décadas pelo legislador brasileiro. O direito ou bem jurídico reconhecidamente protegido exercerá, em seguida, função sistemáticoclassificatória a fim de agrupar e sistematizar os tipos penais na parte especial de forma coerente. Também após o exame da legitimidade do tipo penal se passará a interpretálo, sempre de forma restritiva e conforme os parâmetros constitucionais.

Se “convivem" um Código Penal (ou uma lei penal especial) com uma Constituição de inspirações culturais e ideológicas opostas, como ocorre no Brasil, é preciso urgentemente que se passe a falar, também em âmbito penal, no exercício constante de um controle de constitucionalidade difuso e por via incidental, ou mesmo na interpretação conforme à Constituição, sem que seja preciso esperar por um controle concentrado e pelo reconhecimento erga omnes da ilegitimidade da lei. ${ }^{53}$ Nesse mesmo sentido, STORTONI sugere como duas possibilidades de intervenção em âmbito penal exatamente a declaração de ilegitimidade ou uma interpretação constitucionalmente orientada. ${ }^{54}$

A presença intensa de inconstitucionalidades materiais nas leis penais e processuais penais é algo, enfim, a ser combatido, ao invés de justificado, pela atividade jurisdicional.

\section{CONSIDERAÇÃO FINAL}

O estudo da parte especial - seja do código ou do sistema penal como um todo tem lugar fundamental na minimização do impacto negativo do direito penal sobre os direitos fundamentais, merecendo por isto ser objeto de empenho e reflexão crítica.

\footnotetext{
caso, ad una duplice funzione. In primo luogo, una funzione negativa concernente i limiti dell'intervento penale. In secondo luogo, una funzione positiva in rapporto alla definizione dell'oggetto, possibile ma non necessario, della tutela per mezzo del diritto penale." V. também ROMANO, Bartolomeo. Guida alla parte speciale del diritto penale, p. 31: "non è sempre comunque necessario disporre una tutela penale, posto che spesso esistono altri modi alternativi, e forse più efficaci".
}

${ }^{52}$ HASSEMER, Winfried. "Il bene giuridico nel rapporto di tensione tra costituzione e diritto naturale". Dei Delitti e Delle Pene, p. 108.

${ }^{53}$ Sobre o tema, no Brasil, v. BARROSO, Luís Roberto. O Controle da Constitucionalidade no Direito Brasileiro:exposição sistemática da doutrina e análise crítica da jurisprudência. São Paulo: Saraiva, 2004; STRECK, Lenio Luiz. Jurisdição Constitucional e Hermenêutica. Porto Alegre: Livraria do Advogado, 2002.

${ }^{54}$ STORTONI, Luigi. "Introduzione alla parte speciale". Introduzione al sistema penale: Vol. 1, p. 436. 
Não se visualiza na história legislativa penal brasileira um fenômeno de codificação seguido pela descodificação, enquanto momentos culturais caracterizados pela ocupação de um lugar de centralidade, pelo código, seguido de sua substituição por leis especiais. Em verdade o "código penal brasileiro" esteve sempre acompanhado por vasta legislação penal extravagante, o que indica o perene caráter casuísta e emergencial na tradição legislativa brasileira. Não há sentido, assim, ao menos terminologicamente, falar-se em recodificação como fazem FIANDACA $^{55}$ e MANTOVANI ${ }^{56}$, inseridos em outra realidade. A substância da crítica, porém, é a mesma, no sentido de ser necessária e urgente uma revisão política dos objetivos do sistema penal e a reformulação de sua enorme "parte especial", considerando legítimo apenas o que for verificável como proteção de um direito fundamental de relevância constitucional e que exija como necessária a intervenção penal.

A concretização nos fatos de um direito penal mínimo e constitucionalizado passaria, enfim, por uma atividade interpretativa por um lado inserida no paradigma hermenêutico e, por outro, politicamente comprometida com a sua própria constitucionalização. Tal compromisso, entretanto, implica a corajosa postura de se trabalhar, cotidianamente, com o reconhecimento de ilegitimidade de inúmeras leis penais segundo os parâmetros de um controle de constitucionalidade exercido de forma difusa.

Certamente são muitas as possíveis críticas a esta hipótese, passando pela indicação de um espaço de excessivo protagonismo jurisprudencial em detrimento do papel do legislador, ou mesmo se reconhecendo ceticamente que a mesma cultura antiliberal na qual está imbuída o legislador também alcança boa parte da magistratura nacional.

Não há "respostas prontas" mas antes, e especialmente se tratando de direito penal, a formalização de escolhas e posições políticas. Qualquer mínima mudança e democratização do direito penal passa indubitavelmente por uma transformação cultural que reconheça mais malefícios que benefícios na utilização do caro, corrupto e doloroso aparato penal e, assim, abra os olhos para a grande quantidade de possibilidades de respostas alternativas à resolução de conflitos e à demanda coletiva por segurança.

\section{REFERÊNCIAS}

AAVV. Beni e techniche della tutela penale: materiali per la riforma del codice. Milano: Franco Angeli, 1987.

ALVAREZ GARCÍA, Francisco Javier. "Relaciones entre la parte general y la parte especial del derecho penal". Anuario de Derecho Penal y Ciencias Penales, v. 46, 1993, Madrid: Ministerio de Justicia, p. 1009-1030.

${ }^{55}$ FIANDACA, Giovanni. "La parte speciale tra codificazione e legislazione penale speciale". Prospettive di riforma del codice penale e valori costituzionali, p. 238.

${ }^{56}$ MANTOVANI, Fernando. Diritto Penale: Parte Speciale, v. I. 3. ed. Milano: Cedam, 2008, p. XVI-XVII. 
ANTOLISEI, Francesco. Manuale di diritto penale: parte speciale, vol. 1. 11.ed. Milano: Giuffrè, 1994.

ARGUELLO, Katie. Do Estado Social ao Estado Penal: invertendo o discurso da ordem. "1"

Congresso Paranaense de Criminologia". Londrina, 2005. Disponível em: http://www.cirino.com.br

artigos/Artigo\%20Katie.pdt.

BARATTA, Alessandro. "Principi di diritto penale minimo. Per una teoria dei diritti dell'uomo come oggetto e limite della legge penale". Dei Delitti e Delle Pene, n. 3, 1985, Bari: Ed.Scientifiche Italiane, p. 443-473.

BECCARIA, Cesare. Dos delitos e das penas. Trad. Torrieri Guimarães. São Paulo: Hemus, 1974.

BERTACCINI, Davide; PAVARINI, Massimo. L'altro diritto penale. Percorsi di ricerca sociologica nel diritto penale complementare nelle norme e nei fatti. Torino: Giappichelli, 2004.

BRICOLA, Franco. "Teoria generale del reato". Novissimo Digesto Italiano, vol. XIV. Torino: Utet, 1973, p. 7-93.

CADOPPI, Alberto. "Presentazione". Omnis definitio in jure periculosa? Il problema delle definizioni legali nel diritto penale (Coord. Alberto Cadoppi). Padova: Cedam, 1996, p. 1-30.

CADOPPI, Alberto; VENEZIANI, Paolo. Elementi di Diritto Penale: Parte Speciale. Padova: Cedam, 2004.

CATTANEO, Mario. Illuminismo e legislazione. Milano: Ed. Di Comunità, 1966.

COUTINHO, Jacinto Nelson de Miranda. "Dogmática crítica e limites linguísticos da lei”. Diálogos constitucionais: direito, neoliberalismo e desenvolvimento em países periféricos (Organização de Jacinto Nelson de Miranda Coutinho e Martônio Mont'Alverne Barreto de Lima). Rio de Janeiro: Renovar, 2006, p. 225-232.

COUTINHO, Jacinto Nelson de Miranda. "Prefácio". LOPES JR., Aury. Direito Processual Penal e sua conformidade constitucional. Vol. 1. Rio de Janeiro: Lumen Juris, 2007.

COUTINHO, Jacinto Nelson de Miranda. "Prefácio: O Drama, Hoje, do Direito Penal”. BRANDÃO, Cláudio. Curso de Direito Penal: Parte Geral. Rio de Janeiro: Forense, 2008.

FERRAJOLI, Luigi. Diritto e ragione: Teoria del Garantismo Penale. 7. ed. Bari: Laterza, 2002.

FIANDACA, Giovanni. "La parte speciale tra codificazione e legislazione penale speciale".

Prospettive di riforma del codice penale e valori costituzionali. Milano: Giuffrè, 1996, p. 237-257.

GRAU, Eros Roberto. Ensaio e discurso sobre a interpretação/aplicação do direito. 3. ed. São Paulo: Malheiros, 2005.

HASSEMER, Winfried. "Il bene giuridico nel rapporto di tensione tra costituzione e diritto naturale". Dei Delitti e Delle Pene, n.1, 1984, Bari: Edizione Scientifiche Italiane, p. 104-113.

LUDWIG, Celso Luiz. Para uma Filosofia Jurídica da Libertação: Paradigmas da Filosofia da Libertação e Direito Alternativo. Florianópolis: Conceito Editorial, 2006.

PADOVANI, Tullio; STORTONI, Luigi. Diritto penale e fattispecie criminose. Introduzione alla parte speciale del diritto penale. Bologna: Il Mulino, 1991.

PAVARINI, Massimo. "Per un diritto penale minimo: 'in the books' o 'in the facts'? Discutendo con Luigi Ferrajoli”. Dei Delitti e Delle Pene, n. 3, 1998, Bari: Edizione Scientifiche Italiane, p. 125-156.

PISAPIA, Gian-Domenico. Introduzione alla parte speciale del diritto penale. Milano: Giuffrè, 1948.

PRIETO SANCHÍS, Luis. La filosofía penal de la Ilustración. Lima: Palestra, 2007. 
ROMANO, Bartolomeo. Guida alla parte speciale del diritto penale. Milano: Giuffrè, 2004.

SANTOS, Juarez Cirino dos. "A criminologia crítica e a reforma da legislação penal". Apresentação na XIX Conferência Nacional dos Advogados/OAB. Florianópolis, 2005. Disponível em: http://www. cirino.com.br/artigos/jcs/criminologia_critica_reforma_legis_penal.pdf

SANTOS, Juarez Cirino dos. Direito Penal: Parte Geral. 3. ed. Curitiba: Lumen Juris, ICPC, 2008.

SANTOS, Juarez Cirino dos. "Novas hipóteses de criminalização". Apresentação na XVIII

Conferência Nacional dos Advogados/OAB. Salvador, 2002. Disponível em: http://www. cirino.com. br/artigos/jcs/novas_hipoteses_criminalizacao.pdf

SAUSSURE, Ferdinand de. Curso de Linguística Geral. 27. ed. Tradução de Antônio Chelini, José Paulo Paes e Izidoro Blikstein. São Paulo: Cultrix, 2006.

SILVEIRA, Fabiano Augusto Martins. Do Crescimento do Direito Penal: medições, análises e interação entre ciência e política no processo de reforma legislativa. 2008. Tese (Doutorado em Direito) - Universidade Federal de Minas Gerais.

STORTONI, Luigi. "Introduzione alla parte speciale". Introduzione al sistema penale: Vol. 1 (a cura di Gaetano Insolera, Nicola Mazzacuva, Massimo Pavarini e Marco Zanotti). 3. ed. Torino: G. Giappichelli Editore, 2006, p. 411-443.

STRECK, Lênio Luiz. Hermenêutica jurídica e(m) crise: uma exploração hermenêutica da construção do Direito. 6. ed. Porto Alegre: Livraria do Advogado, 2005.

TARELLO, Giovanni. Storia della cultura giuridica moderna: Assolutismo e codificazione del diritto. Vol. 1. Bologna: Il Mulino, 1976.

TAVARES, Juarez. Teoria do Injusto Penal. Belo Horizonte: Del Rey, 2000.

TOLEDO, Francisco de Assis. Princípios básicos de direito penal. 5. ed. São Paulo: Saraiva, 1987.

WARAT, Luis Alberto. O Direito e sua Linguagem. 2.ed. Porto Alegre: Sérgio Fabris, 1995.

WITTGENSTEIN, Ludwig. Investigações filosóficas. 3. ed. Tradução de Marcos Montagnoli. Petrópolis: Vozes, 2004.

ZAFFARONI, Eugenio Raúl; PIERANGELI, José Henrique. Manual de direito penal brasileiro. 5. ed. São Paulo: Revista dos Tribunais, 2004.

ZAFFARONI, E. Raúl; BATISTA, Nilo; ALAGIA, Alejandro; SLOKAR, Alejandro. Direito Penal Brasileiro. 1. vol. Rio de Janeiro: Revan, 2003. 